\title{
Flume Study for the Prediction of Threshold Velocity of Protection Elements of Revetment Works
}

\author{
Tanzim Ahmed ${ }^{1}$, Md. Abdul Matin ${ }^{2}$ \\ Assistant Professor, Department of Water Resources Engineering, \\ Bangladesh University of Engineering and Technology, Dhaka, Bangladesh ${ }^{1}$ \\ Professor, Department of Water Resources Engineering, \\ Bangladesh University of Engineering and Technology, Dhaka, Bangladesh ${ }^{2}$
}

\begin{abstract}
River bank erosion is commonly counter measured by placing protecting elements. The placement of protecting elements in under water condition has always been a crucial task. In particular the construction works of toe protection like falling apron cannot be properly implemented in a perennial river, where low water level prevails. Placing of underwater apron materials requires a considerably high skilled manpower, equipment and appropriate practical approaches. The present paper aims to undertake experimental investigation on incipient (threshold) condition of toe protection elements under live bed condition. The aim is to provide a simple guideline for the ease of construction. The experiments have been conducted in the Hydraulics and River Engineering Laboratory of Water Resources Engineering Department, BUET. Four types of CC block and five types of geobag have been used. A total of sixteen experimental runs with two different hydraulic conditions have been investigated. Experimental results are analyzed to develop empirical relationships that can be used to predict the shear velocity at incipient condition of toe protection elements. The proposed relationships are also compared with the equations available in earlier studies. Comparisons show that the predictive capacity of the proposed relationships is found satisfactory. It is suggested that the designer should consider the hydraulic parameters which should be commensurate with underwater constructional aspects.
\end{abstract}

Keywords: Flume study, Incipient motion, protection elements, threshold velocity, falling apron.

\section{INTRODUCTION}

River training and bank protection works of alluvial rivers is now a major challenge for engineers. To scour is probably the most frequent cause of failure not only for riprap, but also for a wide variety of protection techniques. To address this problem, artificial covering of the riverbank and bed with erosion resistant material is built. In recent time, concrete blocks and geobags are commonly used as toe protection elements of revetment works. In Bangladesh, river bank and bed protection works are to be constructed in underwater condition. Concrete blocks and geobags are commonly used as toe protection elements of revetment works in recent times. Thus, it is very important to understand the incipient behavior of protection elements in real field condition so that under water construction can be more appropriate.

Limited study has been done on incipient behavior of toe protection elements. Dey and Raju conducted research on incipient motion of gravel and coal beds [1]. Some proposed relationship regarding incipient motion (threshold velocity) [2-5]. An experimental study on settling behavior and incipient condition of toe protection elements in a fixed bed channel was carried out by Raju [6-7]. It is anticipated that the behavior of protection elements will be different under such condition at which the channel bed is composed of sand, flowing under equilibrium condition which is considered as live bed channel.
RRI conducted physical model study to test the performance of geobags and concrete blocks as bank protection works [8]. In underwater condition, identification of placement of protective elements in water flowing situation is found to be more difficult. This has been also reported by Stevens and Oberhagemann [9]. Review of literature shows that no mentionable studies have been conducted to investigate the underwater constructional aspects of toe protection.

In this paper, an attempt has been made to conduct experimental investigation to determine shear velocity at the incipient condition (threshold velocity) of toe protection elements in a laboratory flume under live bed condition.

\section{THEORETICAL ANALYSIS}

Inception of motion is a critical condition that involves many measurable and non-measurable factors. Under critical conditions, the tractive stress of the particle is given by:

$$
\tau_{c}=\frac{c_{1} a_{1}}{c_{2} a_{2}} g\left(\rho_{s}-\rho\right) d_{n} \cos \phi(\tan \theta-\tan \phi)
$$

For a horizontal bed, $\phi=0$, and Equation (1) becomes:

$$
\tau_{c}=\frac{c_{1} a_{1}}{c_{2} a_{2}} g\left(\rho_{s}-\rho\right) d_{n} \tan \theta
$$


When $a_{1}$ and $a_{2}$ are equal the forces on the particle act Using particle shear Reynolds number or boundary through its center of gravity and the fluid forces are caused Reynolds number, $\mathrm{R}_{\mathrm{e}^{*}}$ as predominantly by pressure. Also, when $\mathrm{a}_{1}$ and $\mathrm{a}_{2}$ are equal it will be seen that the ratio of the forces on the particle parallel to the bed i.e. hydrodynamic force, to those acting normal to the bed i.e. immersed weight, is equal to $\tan \theta$, resulting Equation (2) as:

$$
\frac{\tau_{\mathrm{c}}}{\mathrm{g}\left(\rho_{\mathrm{s}}-\rho\right) \mathrm{d}_{\mathrm{n}}}=\mathrm{c} \tan \theta
$$

The left-hand side of equation (3) represents the ratio of two opposing forces: hydrodynamic force and immersed weight, which governs the initiation of motion. Major variables that affect the incipient motion of a particle through a fluid include $\tau_{\mathrm{c}}, \mathrm{d}_{\mathrm{n}}, \rho_{\mathrm{s}}, \rho$ and $\nu$.From dimensional analysis they may be grouped into the following dimensionless parameters

$$
\mathrm{f}\left(\frac{\sqrt{\left({ }^{\tau_{c}} / \rho\right)}}{v}, \frac{\rho \mathrm{W}^{\prime}}{\mu^{2}}\right)=0
$$

in which $\mathrm{u}_{*_{c}}=\sqrt{ }\left(\tau_{\mathrm{c}} / \rho\right)$ is the critical friction velocity or the critical shear velocity, $\quad W^{\prime}=g\left(\rho_{s}-\rho\right) d_{n}{ }^{3}$ is the submerged weight. Again, $u_{*}=$ shear velocity $=\sqrt{ }(\tau / \rho)$; $\tau_{\mathrm{c}}=$ average shear stress at the point of particle motion, where $\tau$ is the average shear stress is a function of the hydraulic radius $(\mathrm{R})$ and slope of the energy line $(\mathrm{S}),(\tau=$ $\rho g R S), d_{n}=$ nominal diameter of the particle. Thus (4) becomes

$$
\mathrm{f}\left(\frac{\mathrm{u}_{*} \mathrm{~d}_{\mathrm{n}}}{\mathrm{v}}, \mathrm{d}_{\mathrm{n}}\left(\frac{\Delta \mathrm{g}}{v^{2}}\right)^{1 / 3}\right)=0
$$

$$
\mathrm{R}_{\mathrm{e}^{*}}=\left(\frac{\mathrm{u}_{*} \mathrm{~d}_{\mathrm{n}}}{v}\right)
$$

and the dimensionless particle diameter, $\mathrm{d}_{*}$ defined as

$$
\mathrm{d}_{*}=\mathrm{d}_{\mathrm{n}}\left(\frac{\Delta \mathrm{g}}{\mathrm{v}^{2}}\right)^{1 / 3}
$$

The first and second non-dimensional term of equation (5) can be replaced by boundary Reynolds number $\left(\mathrm{R}_{\mathrm{e}^{*}}\right)$ defined in equation (6) and dimensionless particle diameter $\left(d_{*}\right)$ defined in equation (7).Inserting $d_{*}$ and $\mathrm{R}_{\mathrm{e} * \text { into equation (5) results in: }}$

$$
\mathrm{R}_{\mathrm{e} *}=\mathrm{f}\left(\mathrm{d}_{*}\right)
$$

In this study an attempt has been made to predict critical shear velocity at incipient condition (threshold velocity) through a simple relationship as in Equation (8).

\section{EXPERIMENTATION}

Experiments have been carried out in the Hydraulics and River Engineering Laboratory of the Department of Water Resources Engineering (DWRE) of BUET, Dhaka. The test section is selected in the experimental reach of the setup. The experimental reach is a sand bed trapezoidal channel of length about 12.75 meters, bottom width 0.60 $\mathrm{m}$, top width $1 \mathrm{~m}$ and height $0.4 \mathrm{~m}$. The right bank of the channel is vertical and left bank is sloping with 1:1 slope.

Fig. 1 is showing the dimensions of experimental reach. Fig. 2 shows the design scour depth which was estimated by Lacey's regime formula as it is widely used in this subcontinent in alluvial rivers.

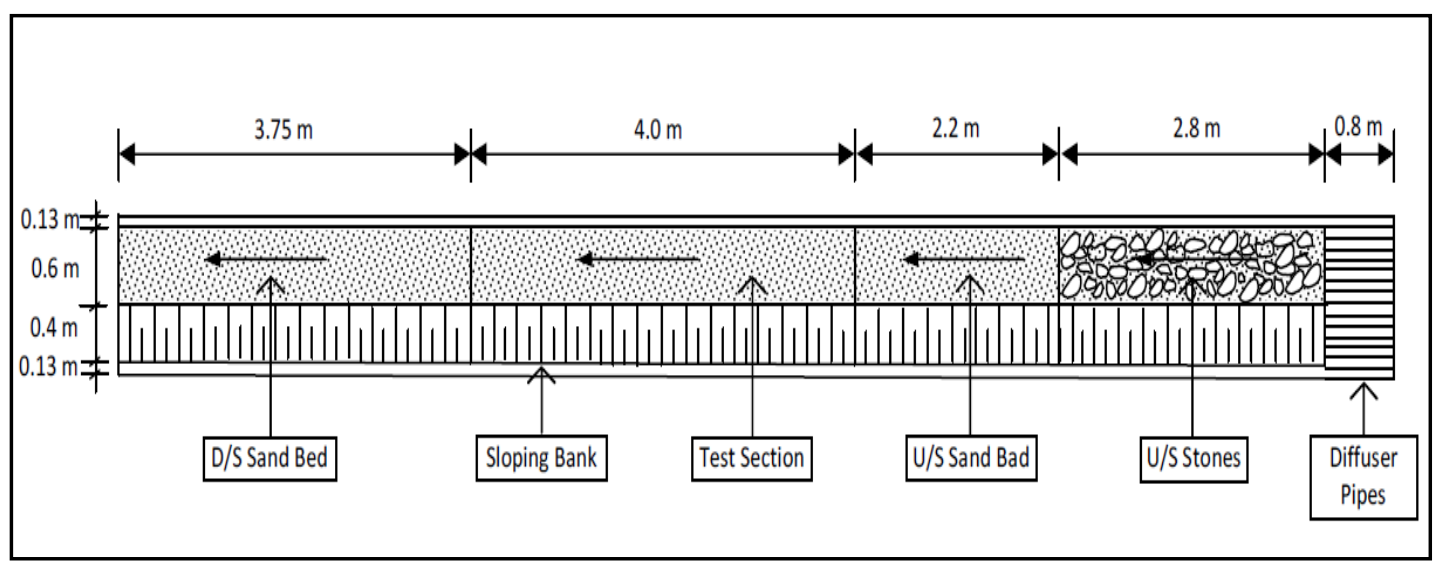

Fig.1. Dimensions of experimental reach

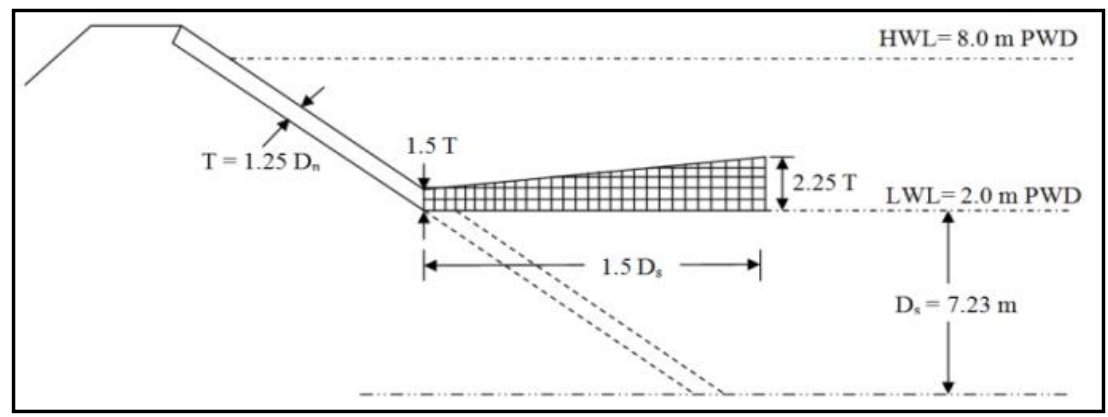

Fig.2. Schematic diagram for shape of Apron for a typical field condition 
The test section has been selected based on numbers of trial run when the uniform flow achieved and no backwater effect in the reach was found. A geometrically similar undistorted scale factor 20 was selected to conduct the experiment. This selection of scale was based on (i) the available laboratory flume facilities and (ii) the Froude law criteria.

It was assumed that the material and porosity remained unchanged for the experiment and prototype. Therefore, protection elements used for the laboratory experiment should be the same as those designed for field construction except for the reduced dimension [10]. The dimensions of blocks are listed in Table 1.The dimensions of the bags are listed in Table 2. The length to width ratio ranges from 1.73 to 1.09

TABLE 1 DIMENSION OF CC BLOCKS USED IN THE EXPERIMENT

\begin{tabular}{|c|c|c|c|}
\hline Type of block & $\begin{array}{c}\text { Length } \\
(\mathbf{m m})\end{array}$ & $\begin{array}{c}\text { Width } \\
\text { (mm) }\end{array}$ & $\begin{array}{c}\text { Thickness } \\
(\mathbf{m m})\end{array}$ \\
\hline Concrete block (C1) & 22.90 & 23.16 & 24.10 \\
\hline Concrete block (C2) & 20.98 & 20.72 & 20.48 \\
\hline Concrete block (C3) & 15.96 & 15.98 & 16.02 \\
\hline Concrete block (C4) & 10 & 9.3 & 9.6 \\
\hline
\end{tabular}

TABLE 2 DIMENSIONS OF GEOBAGS USED IN THE EXPERIMENT

\begin{tabular}{|l|c|c|c|}
\hline $\begin{array}{l}\text { Type of } \\
\text { Geobag }\end{array}$ & $\begin{array}{c}\text { Length } \\
\text { (mm) }\end{array}$ & $\begin{array}{c}\text { Width } \\
\text { (mm) }\end{array}$ & $\begin{array}{c}\text { Thickness } \\
\text { (mm) }\end{array}$ \\
\hline Geobag (G1) & 71.20 & 40.90 & 10.9 \\
\hline Geobag (G2) & 51.60 & 29.805 & 8.60 \\
\hline Geobag (G3) & 42.90 & 38.00 & 9.04 \\
\hline Geobag (G4) & 60.24 & 38.60 & 7.02 \\
\hline Geobag (G5) & 51.94 & 47.70 & 7.02 \\
\hline
\end{tabular}

Different protection elements used for the present study are shown in Fig. 3.

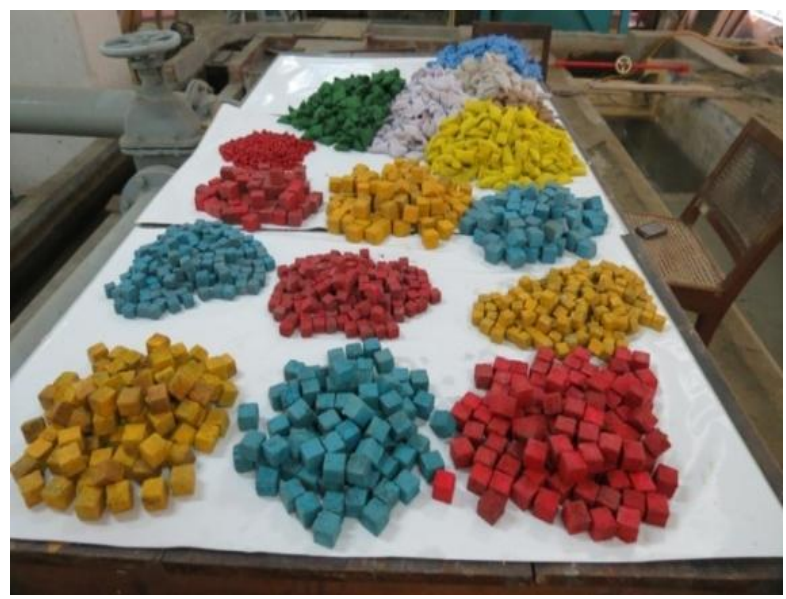

Fig.3. CC blocks and geobags used in the experiment

\section{A. Test scenarios}

Experiments were conducted with four types of CC block and five types of geobag with two different hydraulic conditions to investigate incipient condition as presented in Table 3.
TABLE 3 TEST SCENARIOS FOR INVESTIGATION OF INCIPIENT CONDITION

\begin{tabular}{|c|c|c|c|}
\hline $\begin{array}{c}\text { Run } \\
\text { no. }\end{array}$ & $\begin{array}{c}\text { Discharge } \\
\text { range } \\
(\mathbf{m} 3 / \mathbf{h})\end{array}$ & $\begin{array}{c}\text { Water level } \\
\text { range(m) }\end{array}$ & $\begin{array}{l}\text { Type of } \\
\text { Protection } \\
\text { Element }\end{array}$ \\
\hline 1 & \multirow{4}{*}{150 to 300} & \multirow{4}{*}{0.15 to 0.19} & $\begin{array}{c}\text { Concrete block } \\
\text { (C1) }\end{array}$ \\
\hline 2 & & & $\begin{array}{c}\text { Concrete block } \\
\text { (C2) }\end{array}$ \\
\hline 3 & & & $\begin{array}{c}\text { Concrete block } \\
\text { (C3) }\end{array}$ \\
\hline 4 & & & $\begin{array}{c}\text { Concrete block } \\
\text { (C4) }\end{array}$ \\
\hline 5 & \multirow{3}{*}{195 to 320} & \multirow{3}{*}{0.175 to 0.21} & $\begin{array}{c}\text { Concrete block } \\
\text { (C1) }\end{array}$ \\
\hline 6 & & & $\begin{array}{c}\text { Concrete block } \\
\text { (C2) }\end{array}$ \\
\hline 7 & & & $\begin{array}{c}\text { Concrete block } \\
\text { (C3) }\end{array}$ \\
\hline 8 & \multirow{5}{*}{130 to 270} & \multirow{5}{*}{0.15 to 0.22} & Geobag (G1) \\
\hline 9 & & & Geobag (G2) \\
\hline 10 & & & Geobag (G3) \\
\hline 11 & & & Geobag (G4) \\
\hline 12 & & & Geobag (G5) \\
\hline 13 & \multirow{4}{*}{165 to 295} & \multirow{4}{*}{0.175 to 0.24} & Geobag (G2) \\
\hline 14 & & & Geobag (G3) \\
\hline 15 & & & Geobag (G4) \\
\hline 16 & & & Geobag (G5) \\
\hline
\end{tabular}

B. Measurements and observations

The shape of apron and number of element required per unit length was determined as mentioned previously. Depth of flow was measured by point gauge. Point velocity data were collected by using ADV (Acoustic Doppler Velocimeter) at apron and just upstream of the apron. During experiments, the following observations were made:

i) The water surface at the apron section was slightly lower than the upstream section.

ii) The velocity over the apron was higher than that of upstream and downstream.

iii) The larger the size of the protection element greater velocity required to cause incipient condition.

iv) As the velocity was increased the protection elements started vibrating.

v) For geobags, group movement or sliding was observed while blocks moved individually.

vi) Square shaped bags required higher velocity to reach incipient condition than that of rectangular bags.

\section{RESULTS AND DISCUSSIONS}

A. Analysis of shear velocity for CC block

Two set up were investigated for both block and geobag during the sixteen experimental runs (seven for block and nine for geobag) to obtain a correlation between dimensionless particle diameters with dimensionless flow parameter boundary Reynolds number. On the basis of expression shown in equation (8), a regression analysis of the experimental data has been performed with a coefficient of determination $\left(\mathrm{R}^{2}\right)$ of 0.997 . 
International Advanced Research Journal in Science, Engineering and Technology

Vol. 3, Issue 1, January 2016

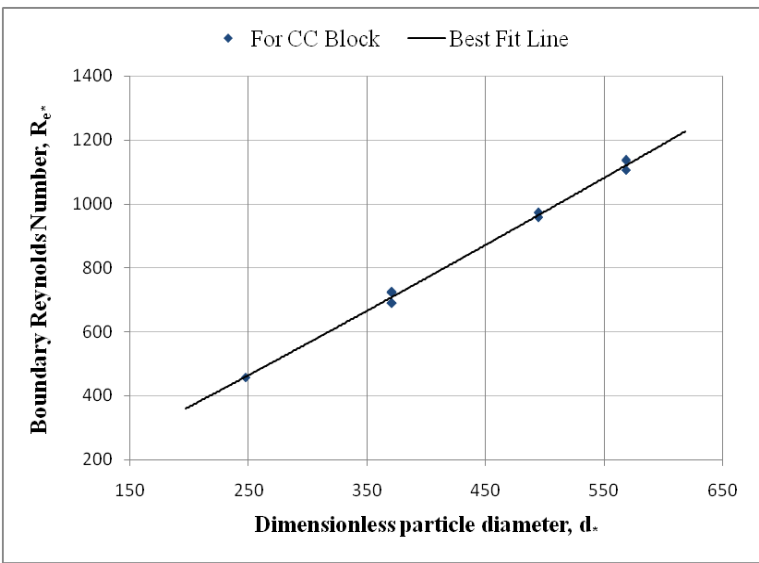

Fig.4. Boundary Reynolds number versus dimensionless particle diameter for $\mathrm{CC}$ Block

Finally equation (8) for $\mathrm{CC}$ blocks attains the form as:

$$
\mathrm{R}_{\mathrm{e}^{*}}=1.212 \mathrm{~d}_{*}{ }^{1.076}
$$

It is seen from Fig.4 boundary Reynolds number increases as the dimensionless particle diameter increases.

B. Comparison of proposed shear velocity equation for CC block

Fig. 5 represents the values of discrepancy ratios of predicted shear velocity and observed shear velocity by proposed empirical equation (9). This Figure also shows the values of other researchers such as Keulegan (1938) [11], Manning and Strickler equation [12] and Melville (1988) [13]. Table 4 shows the percentage of discrepancy ratios within each discrepancy band.

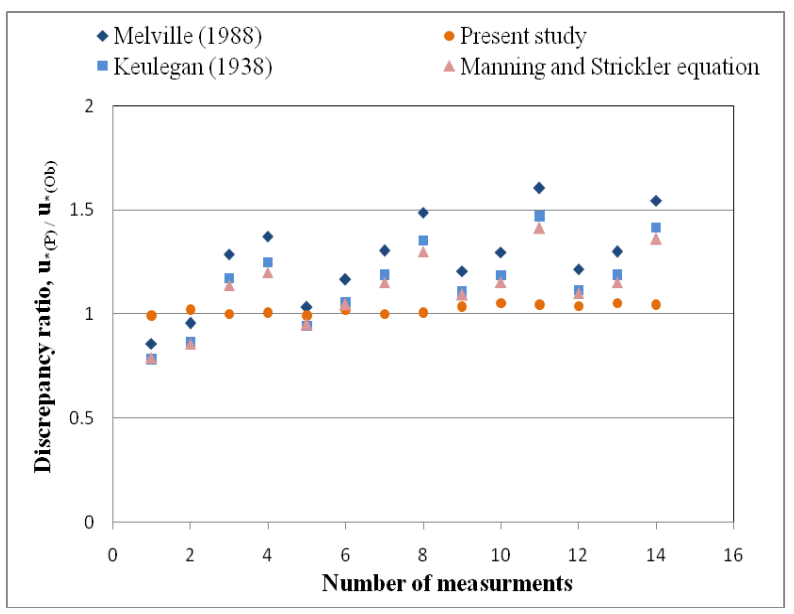

Fig.5. Values of discrepancy ratio of shear velocity for CC block

The values of discrepancy ratio as shown in Fig.5 and Table 4 demonstrate that $100 \%$ of the present experimental data lies within the range of 0.95 to 1.05 . The different percentage of discrepancy ratio of Keulegan (1938) [11], Manning and Strickler equation [12] and Melville (1988) [13] equations are found within different bands. These analysis reveals that the present equation show comparatively better predictive performance of shear velocity than earlier investigations.
TABLE 4 DISCREPANCY BAND OF SHEAR VELOCITY FOR CC BLOCK

\begin{tabular}{|c|c|c|c|c|}
\hline $\begin{array}{c}\text { Discre } \\
\text { pancy } \\
\text { Band }\end{array}$ & $\begin{array}{c}\text { Present } \\
\text { Study } \\
(\%)\end{array}$ & $\begin{array}{c}\text { Keulega } \\
\mathrm{n}(1938) \\
(\%)\end{array}$ & $\begin{array}{c}\text { Manning } \\
\text { \&Strickl } \\
\text { er Eq. } \\
(\%)\end{array}$ & $\begin{array}{c}\text { Melvill } \\
\mathrm{e} \\
(1988) \\
(\%)\end{array}$ \\
\hline $0.95-1.05$ & 100 & 0 & 15 & 15 \\
\hline $0.85-1.15$ & - & 36 & 43 & 22 \\
\hline $0.75-1.25$ & - & 79 & 79 & 43 \\
\hline $0.65-1.35$ & - & 100 & 86 & 72 \\
\hline $0.5-1.5$ & - & - & 100 & 86 \\
\hline $0.5-2.0$ & - & - & - & 100 \\
\hline
\end{tabular}

C. Analysis of shear velocity for geobag

On the basis of expression shown in equation (8), a regression analysis of the experimental data has been performed. The plot is shown in Fig. 6.

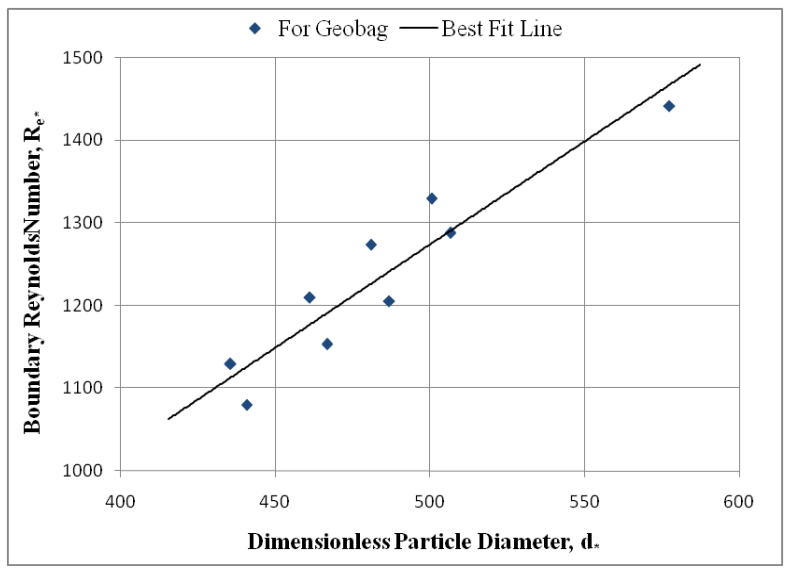

Fig.6. Boundary Reynolds number versus Dimensionless particle diameter for geobag

The coefficient of determination $\left(\mathrm{R}^{2}\right)$ is found to be 0.87 indicating a good correlation. It is seen that as the dimensionless particle diameter increases the boundary Reynolds number also increases which is consistent with literature. The final expression for shear velocity for geobag becomes:

$$
\mathrm{R}_{\mathrm{e}^{*}}=2.883 \mathrm{~d}_{*}^{0.98}
$$

It is seen that boundary Reynolds number increases as the dimensionless particle diameter increases.

D. Comparison of proposed shear velocity equation for geobag

Fig.7 represents the discrepancy ratio of predicted shear velocity and observed shear velocity by proposed empirical equation (10) for geobag in this study. In this figure, the values of other researchers such as Keulegan (1938) [11], Manning and Strickler equation [12] and Melville (1988) [13] also presented. According to present study all ratios are found to be very close to the perfect agreement line as shown in Fig.7. The discrepancy ratios 
International Advanced Research Journal in Science, Engineering and Technology

of Keulegan (1938) [11], Manning and Strickler equation [12] and Melville (1988) [13] equations lie between the bands 0.5 to 2.0. Table 5 represents the percentage of discrepancy ratios within each discrepancy band for geobags.

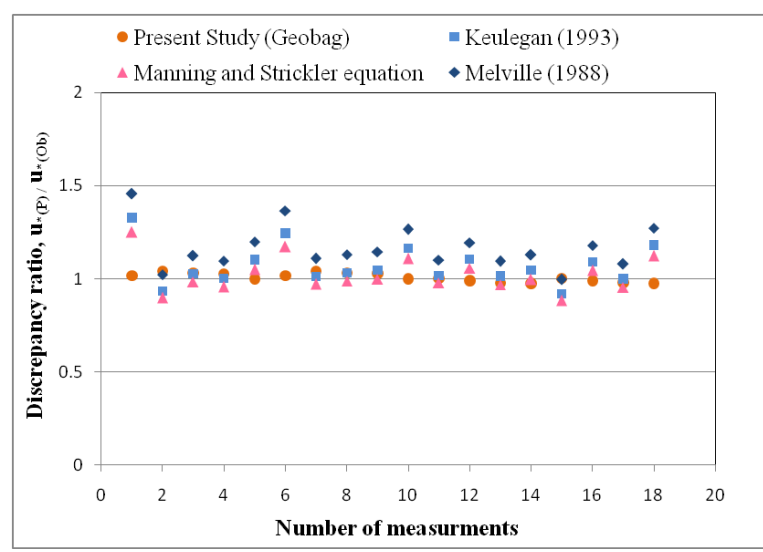

Fig.7. Values of discrepancy ratio of shear velocity for geobags

TABLE 5 DISCREPANCY BAND OF SHEAR VELOCITY FOR GEOBAG

\begin{tabular}{|c|c|c|c|c|}
\hline $\begin{array}{c}\text { Discrepa } \\
\text { ncy } \\
\text { Band }\end{array}$ & $\begin{array}{c}\text { Presen } \\
\text { t Study } \\
(\%)\end{array}$ & $\begin{array}{c}\text { Keuleg } \\
\text { an } \\
(1938) \\
(\%)\end{array}$ & $\begin{array}{c}\text { Manning } \\
\text { \&Strickle } \\
\text { r Eq. (\%) }\end{array}$ & $\begin{array}{c}\text { Melville } \\
(1988) \\
(\%)\end{array}$ \\
\hline $0.95-1.05$ & 100 & 50 & 62 & 12 \\
\hline $0.85-1.15$ & - & 78 & 89 & 62 \\
\hline $0.75-1.25$ & - & 95 & 100 & 78 \\
\hline $0.65-1.35$ & - & 100 & - & 89 \\
\hline $0.5-1.5$ & - & - & - & 100 \\
\hline
\end{tabular}

From Table 5 it is found that $100 \%$ ratios within the range of 0.95 to 1.05 . The different percentage of discrepancy ratio of Keulegan (1938) [11], Manning and Strickler equation [12] and Melville (1988) [13] equations are found within different bands. These analysis reveals that the present equation show better predictive performance of shear velocity for geobags than earlier investigations.

E. Computation of relative error of shear velocity equations

Empirical equation (9) and equation (10) has been developed based on shear velocity by doing experimental investigations at incipient condition of nine different size protection elements for different set ups. Different formulas for shear velocity prediction along with proposed relationship have been compared with observed shear velocity in this study. The relative error of different formula and proposed equation is presented in Table 6 .

From the Table 6, it is found that, the proposed empirical equations have the lowest average value of relative error for block and geobag. However, it is approved that equation (9) and (10) is always a better predictor for block and geobag, respectively, than that of earlier investigations.
TABLE 6 PERFORMANCE OF VARIOUS SHEAR VELOCITY PREDICTION FORMULAS

\begin{tabular}{|l|c|c|}
\hline \multirow{2}{*}{ Shear Velocity Equation } & \multicolumn{2}{|c|}{ Relative Error \% } \\
\cline { 2 - 3 } & CC Block & Geobag \\
\hline Present study & 2.50 & 1.97 \\
\hline Keulegan (1938) & 20.84 & 8.69 \\
\hline $\begin{array}{l}\text { Manning and Strikler } \\
\text { equation }\end{array}$ & 18.03 & 6.84 \\
\hline Melville (1988) & 28.61 & 16.47 \\
\hline
\end{tabular}

The errors in predicting shear velocity by the previous investigations of similar condition are mainly due to the fact that the size of the elements used in this experiment is quite larger than those used in other studies.

These analysis reveals that the present equation show better predictive performance of shear velocity for geobags and blocks than earlier investigations. Present study investigated incipient (threshold) condition of protection element dumped in flowing water on a live bed to better understand the real life phenomena and all the proposed equations have lowest value of relative error comparing with the previously established formula.

\section{CONCLUSION}

Based on experimental data an empirical equation for shear velocity and dimensionless particle diameter has been developed. This equation is compared with earlier investigations. Comparison shows that this equation complies relatively better than works done by other investigators. The relative error of present shear velocity equation is $2.5 \%$ for CC blocks and $1.97 \%$ for geobags. At incipient (threshold) condition, geobags showed comparatively higher shear velocity than that of $\mathrm{CC}$ blocks. These higher values were due to the embedded effect of geobag with sand bed compared to that of $\mathrm{CC}$ blocks. This is also evident from the laboratory observation. It indicates underwater performance of geobag is relatively stable than that of CC block. From the experiment it reveals that the shear velocity required for incipient motion was much higher for geobag when compared with CC block.

\section{REFERENCES}

[1] S. M. Metev and V. P. Veiko, Laser Assisted Microtechnology, 2nd ed., R. M. Osgood, Jr., Ed. Berlin, Germany: Springer-Verlag, 1998.

2] Inglis, C. C. (1949). "The behavior and control of rivers and canals (with the aid of models)", Part II. Central Waterpower Irrigation and Navigation Research Station, Poona, India.

[3] Neill, C. R. (1967). "Mean velocity criterion for scour of coarse uniform bed material". Proceedings $12^{\text {th }}$ Congress, International Association for Hydraulic Research, Vol. 3. (Source: NHC,2006).

[4] Maynord, S. T., Ruff, J. F. and Abt, S. R. (1989). "Riprap Design". J. Hydraul. Eng., ASCE, 115 (7), 937-949.

[5] Northwest Hydraulic Consultants. "Physical Model Study (Vancouver Canada), Final Report. Prepared for Jamuna-Meghna River Erosion Mitigation Project”. Bangladesh Water Development Board.

[6] Raju, K.M.A.H., "An experimental study on settling behavior of toe protection elements of river bank protection works," M.Sc. Thesis, Department of Water Resources Engineering, BUET, Dhaka. 
[7] Raju, K.M.A.H. and Matin M. A. (2013). “An experimental study on settling velocity of regular shaped elements for underwater erosion protection." Journal of Civil Engineering, IEB, 41(1) (2013), 41-58.

[8] River Research Institute. "Additional test to carryout investigation regarding performance of falling apron, drop test for dumping of geobag and outflanking problem by physical model to address bank erosion of Bangladesh". Prepared for Bangladesh Water Development Board.

[9] Stevens, M. A., and Oberhagemann, K. (2006). SpecialReport 17: "Geobag Revetments. Prepared for Jamuna-Meghna River Erosion Mitigation Project". Bangladesh Water Development Board.

[10] FAP 21 (2001). "Guidelines and design manual for standardized bank protection structures", Flood Action Plan, Bank Protection Pilot Project, prepared for Water Resources Planning Organization.

[11] Keulegan, G. H. (1938). "Laws of turbulent flow in open channels". (Vol. 21, pp. 707-741). US: National Bureau of Standards.

[12] Sadat-Helbar, S. M., \&Farhoudi, J. (2008). "Shear velocity method to riprap sizing at downstream of stilling basins". World Applied Sciences Journal, 4(1), 116-123.

[13] Melville, B. W., \& Sutherland, A. J. (1988). "Design method for local scour at bridge piers. Journal of Hydraulic Engineering". 114(10), 1210-1226 